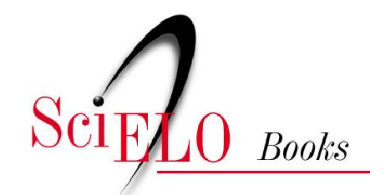

\title{
Reforma sanitária, hegemonia e a efetividade do controle social
}

\author{
Alessandra Ximenes da Silva
}

SILVA, AX. Reforma sanitária, hegemonia e a efetividade do controle social. In DAVI, J., MARTINIANO, C., and PATRIOTA, LM., orgs. Seguridade social e saúde: tendências e desafios [online]. 2nd ed. Campina Grande: EDUEPB, 2011. pp. 117-146. ISBN 978-85-7879-193-3. Available from SciELO Books < $\underline{\text { http://books.scielo.org>. }}$

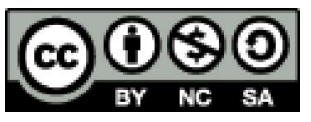

All the contents of this work, except where otherwise noted, is licensed under a Creative Commons Attribution-Non Commercial-ShareAlike 3.0 Unported.

Todo o conteúdo deste trabalho, exceto quando houver ressalva, é publicado sob a licença Creative Commons Atribuição Uso Não Comercial - Partilha nos Mesmos Termos 3.0 Não adaptada.

Todo el contenido de esta obra, excepto donde se indique lo contrario, está bajo licencia de la licencia Creative Commons Reconocimento-NoComercial-CompartirIgual 3.0 Unported. 


\title{
Reforma sanitária, hegemonia e a efetividade do controle social
}

\author{
Alessandra Ximenes da Silva
}

\section{Introdução}

Esse artigo analisa a trajetória histórico-conceitual dos 20 anos do controle social democrático no Brasil, identificando os impasses e interesses que impedem, nos espaços desse controle, a efetivação para a construção de uma nova hegemonia no direcionamento das políticas de saúde na contemporaneidade. $\mathrm{Na}$ perspectiva da Reforma Sanitária Brasileira construída na década de 1980. O Movimento Sanitário, sujeito político coletivo fundamental na formulação do Projeto de Reforma Sanitária nos anos 1980, ficou recuado a partir dos anos 90 . As suas principais entidades não estão conseguindo articular propostas nacionais que fortaleçam a continuidade da Reforma Sanitária Brasileira. Desse modo, apesar de todas as reflexões que explicitam os limites dos espaços de controle social, na perspectiva de uma participação efetiva, considera-se que esses mecanismos são importantes para a democratização do espaço público e para a mudança da cultura política brasileira. Uma efetiva contra-hegemonia depende de compreendermos as condições da classe subalterna, com todas as dificuldades que envolvem na atualidade. A sociedade civil é arena de luta de classes. 
O sentido do controle social democrático, inscrito na Constituição de 1988 é o da participação da população na perspectiva de elaborar, implementar e fiscalizar as políticas sociais. Esta concepção tem como marco o processo de redemocratização da sociedade brasileira com o aprofundamento do debate referente à democracia. Os conselhos e conferências de saúde foram propostos numa conjuntura de mobilização da sociedade civil e foram implementados, a partir dos anos 1990, num cenário de regressão dos direitos sociais e de destruição das conquistas históricas dos trabalhadores em nome da defesa do mercado e do capital.

A partir da Década de 1990, consolida-se a hegemonia do Projeto Neoliberal no Brasil, o que acarretou retrocessos, nos avanços obtidos na década anterior, no que diz respeito ao acesso e as novas formas de gestão das políticas sociais. Observa-se, a partir de tal conjuntura, uma tendência ao esvaziamento e despolitização dos conselhos e conferências enquanto espaços de formulação e decisão da política de saúde.

O Movimento Sanitário, sujeito político coletivo fundamental na formulação do Projeto de Reforma Sanitária nos anos 1980, ficou recuado a partir da década de 1990. A agenda de lutas tem se restringido à implementação do Sistema Único de Saúde, que por sua vez, não engloba todas as proposições anteriormente defendidas.

A análise que se faz após o primeiro governo Lula e os encaminhamentos do segundo mandato é que a disputa entre os dois projetos na saúde - existentes nos anos 1990 - continua. Algumas propostas procuram enfatizar a Reforma Sanitária, mas não tem havido vontade política e financiamento para viabilizá-las.

Identificam-se, também mudanças no discurso dos protagonistas do Projeto de Reforma Sanitária, principalmente a partir de 2007. Há uma flexibilização de suas proposições pautadas nas possibilidades de ação no atual contexto brasileiro. Diversos sujeitos políticos 
coletivos do Movimento de Reforma Sanitária e participantes dos conselhos e das conferências de saúde não têm enfrentado a questão central do governo que é a subordinação da política social à política macroeconômica.

Desse modo, nossa questão central é identificar as determinações sócio-históricas do posicionamento atual, dos sujeitos políticos coletivos da Reforma Sanitária dos anos 1980, que não lutam na atualidade pela construção de uma nova hegemonia. As atuais transformações societárias em curso e suas inflexões sobre a questão da saúde no Brasil vêm determinando novas demandas e respostas no âmbito de atuação desses sujeitos políticos coletivos nos espaços de controle social democrático.

\section{A hegemonia do projeto neoliberal e a reforma sanitária brasileira}

Tratar da questão da Reforma Sanitária Brasileira (RSB) construída a partir da segunda metade da década de 1970 remete às implicações teórico-metodológicas que perpassm a construção desse processo que nas décadas de 1980, 1990 e no Século XXI, tomam configurações e direcionamento políticos diferenciados. Vários teóricos desse processo têm mudado suas concepções construídas ao longo dos anos 1980.

O Projeto de RSB na década de 1980 foi formulado com os princípios da saúde enquanto direito e dever do Estado, o acesso universal e igualitário às ações e serviços para sua promoção, proteção e recuperação, com ênfase nas seguintes diretrizes: descentralização, com direção única em cada esfera de governo; atendimento integral, com prioridade para as atividades preventivas, sem prejuízo dos serviços assistenciais e participação da comunidade. 
No entanto, passados 20 anos desse processo com a implementação do Sistema Único da Saúde (SUS), identificam-se avanços significativos na RSB na década de 1980; mas, na década de 1990, segundo Paim (2008), os obstáculos constatados propiciaram o aparecimento de uma segunda tese: o Projeto da Reforma Sanitária havia se esgotado, apesar do Movimento Sanitário recusar tal conclusão.

O processo se iniciou em meados dos anos 1970 e teve como liderança intelectual e política, o autodenominado "Movimento Sanitário".Tratava-se de um grupo restrito de intelectuais, médicos e lideranças políticas do setor saúde. Gerschman (1995) avalia que este grupo influenciou fundamentalmente o âmbito acadêmico e pode ser considerado como o mentor do processo de reformulação do setor. Foi influenciado pelo modelo da Reforma Sanitária Italiana. De acordo com Fleury (1989), o projeto reformador sustentou-se em uma ampla crítica do modelo prevalecente, baseado no crescimento do setor privado à custa do setor público (o primeiro sendo financiado pelo segundo), o que levou à falência, deterioração, ineficiência e crise do setor público de saúde.

Nos anos 1980, a sociedade brasileira, ao mesmo tempo em que vivenciou um processo de democratização política, superando o regime ditatorial instaurado em 64, experimentou uma profunda e prolongada crise econômica que persiste até os dias atuais. Segundo Bravo (2006, p. 95), "as decepções com a transição democrática ocorreram, principalmente, com seu giro conservador após 1988, não se traduzindo em ganhos materiais para a maioria da população".

Nessa década, a saúde significativamente contou com a participação de novos sujeitos políticos coletivos na discussão das condições de vida da população brasileira e das propostas governamentais apresentadas para o setor, contribuindo para um amplo debate que permeou a sociedade civil. A saúde deixou de ser interesse apenas dos técnicos para assumir uma dimensão política, 
estando estreitamente vinculada à democracia. Dos sujeitos políticos coletivos que tiveram participação preponderante nesse processo, destacam-se: os profissionais de saúde, representados pelas suas entidades, que ultrapassaram o corporativismo, defendendo questões mais gerais como à melhoria da situação saúde e o fortalecimento do setor público; o Movimento Sanitário, teve o CEBES (Centro Brasileiro de Estudos de Saúde) como veículo de difusão e ampliação do debate em torno da Saúde e Democracia e elaboração de contrapropostas; os partidos políticos de oposição, que começaram a colocar nos seus programas a temática e viabilizaram debates no Congresso para discussão da política do setor, e os movimentos sociais urbanos, que realizaram eventos em articulação com outras entidades da sociedade civil.

O texto constitucional, com relação à saúde, após vários acordos políticos e pressão popular, atende em grande parte às reivindicações do Movimento Sanitário, prejudica os interesses empresariais do setor hospitalar e não altera a situação da indústria farmacêutica. Para Fleury (1989), os principais aspectos aprovados na nova Constituição foram: o direito universal à saúde e o dever do Estado, acabando com as discriminações existentes entre segurado/ não-segurado, rural/urbano; as ações e serviços de saúde passaram a ser consideradas de relevância pública, cabendo ao poder público sua regulamentação, fiscalização e controle; constituição do SUS, integrando todos os serviços públicos em uma rede hierarquizada, regionalizada, descentralizada e de atendimento integral, com participação da comunidade; a participação do setor privado no sistema de saúde deverá ser complementar, preferencialmente com as entidades filantrópicas, sendo vedada à destinação de recursos públicos para subvenção às instituições com fins lucrativos. Os contratos com entidades privadas prestadoras de serviços far-seão mediante contrato de direito público, garantindo ao Estado o poder de intervir nas entidades que não estiverem seguindo os termos contratuais. 
Apesar das importantes conquistas de 1988, que anunciavam uma importante reforma democrática do Estado Brasileiro e da política social, engendrando um formato social-democrata com mais de 40 anos de atraso, as condições econômicas internas e internacionais eram extremamente desfavoráveis. Apesar do ascenso das lutas democráticas e dos movimentos sociais, que apontavam condições políticas e uma base de legitimidade forte para a realização de reformas efetivas, muitas contratendências se interpuseram a essa possibilidade. De acordo com Behring e Boschetti (2007, p.147):

Os anos 1990 até os dias de hoje têm sido de contra-reforma do Estado e de obstaculização e/ou redirecionamento das conquistas de 1988, num contexto em que foram derruídas até mesmo aquelas condições políticas por meio da expansão do desemprego e da violência. A afirmação da hegemonia neoliberal no Brasil tem sido responsável pela redução dos direitos sociais e trabalhistas, desemprego estrutural, precarização do trabalho, desmonte da previdência pública, sucateamento da saúde e educação.

Para Bravo (2006, p. 100):

a proposta de política de saúde construída na Década de 80 tem sido desconstruída. A saúde fica vinculada ao mercado, enfatizando-se as parcerias com a sociedade civil, responsabilizando a mesma para assumir os custos da crise

Um dos gargalos da política de saúde é o percentual de recursos financeiros federais previstos inicialmente na Constituição Federal para o SUS, cujo montante totalizava mais que o dobro do orçamento do Ministério da Saúde, nunca foi cumprido pela política econômica e que a partir da década de 1990 até os dias atuais, 
apresenta-se queda na receita do orçamento da saúde dos estados e municípios, que é agora por estes ultrapassados.

Bravo (2006) ressalta essa tendência ao comprometimento da possibilidade de avanço do SUS, enquanto política social, entre as quais se destacam: o desrespeito ao princípio da equidade na alocação dos recursos públicos pela não unificação dos orçamentos federal, estaduais e municipais; o afastamento do princípio da integralidade, ou seja, indissolubidade entre prevenção e atenção curativa, com prioridade para a assistência médico-hospitalar em detrimento das ações de promoção e proteção da saúde.A proposta de Reforma do Estado para o setor saúde ou contra-reforma, era de dividir o SUS em dois - o hospitalar e o básico.

Nessa perspectiva, a saúde fica vinculada ao mercado, enfatizando-se as parcerias com a sociedade civil, responsabilizando a mesma para assumir os custos da crise. A refilantropização é uma das suas manifestações com a utilização de agentes comunitários e cuidadores para realizarem atividades profissionais, com o objetivo de reduzir os custos. Além do aumento da precarização do trabalho no setor saúde. $\mathrm{Na}$ atualidade, os trabalhadores são contratados através de cooperativas, fundações estatais de direito privado e associações de moradores para prestarem serviços em unidades ou programas vinculados ao SUS. Enfatizamos aqui o Programa Saúde da Família (PSF) que deveria ser uma estratégia significativa de assistência a atenção básica, mas o seu formato no Brasil, tem apresentado a sua pouca efetividade, passando a ser mais um programa focal do governo federal.

A tendência geral tem sido a de restrição e redução de direitos, sob o argumento da crise fiscal do Estado, transformando as políticas sociais - a depender da correlação de forças entre as classes sociais e segmentos de classe e do grau de consolidação da democracia e da política social nos países - em ações pontuais e compensatórias direcionadas para os efeitos mais perversos da crise. 
De acordo com Mota (1995, p. 122)

a tendência é privatizar os programas de previdência e saúde e ampliar os programas assistenciais, em sincronia com as mudanças no mundo do trabalho e com as propostas de redirecionamento da intervenção social do Estado.

Para Behring e Boschetti (2007), na saúde, o principal paradoxo é que o SUS, fundado nos princípios de universalidade, equidade, integralidade das ações, regionalização, hierarquização, descentralização, participação da comunidade e complementaridade do setor privado, vem sendo minado pela qualidade de serviços ruins, pela falta de recursos, pela ampliação da prestação de serviços privados que sugam os recursos públicos e pela instabilidade no financiamento. As propostas de saúde pública, defendida pelo Movimento da Reforma Sanitária, várias de suas concepções foram incorporadas na Constituição de 1988, no entanto, "parece estar na prática, sofrendo um processo de privatização ou de uma democracia inconclusa" (Gerschman, 1995, p. 02).

Desse modo, dois projetos convivem em tensão: o Projeto de Reforma Sanitária, construído na década de 1980 e inscrito na Constituição Brasileira de 1988, e o Projeto Neoliberal ou privatista, hegemônico na segunda metade da década de 1990 (BRAVO, 2006).

O projeto saúde, articulado ao mercado, ou a reatualização do modelo médico assistencial privatista, está pautado na política de ajuste, que tem como principais tendências a contenção dos gastos com racionalização da oferta e a descentralização com isenção de responsabilidade do poder central. Segundo Bravo (2006, p.79):

A tarefa do Estado, nesse projeto, consiste em garantir um mínimo aos que não podem pagar, ficando para o setor privado o atendimento dos que têm acesso ao mercado. Suas principais 
propostas são: caráter focalizado para atender às populações vulneráveis através do pacote básico para a saúde, ampliação da privatização, estímulo ao seguro privado, descentralização dos serviços ao nível local, eliminação da vinculação de fonte com relação ao financiamento.

A universalidade do direito - um dos fundamentos centrais do SUS e contido no Projeto de Reforma Sanitária - foi um dos aspectos que têm provocado resistência dos formuladores do projeto saúde voltado para o mercado. Esse projeto tem como premissa concepções individualistas e fragmentadoras da realidade, em contraposição às concepções coletivas e universais do projeto contra-hegemônico.

Observa-se que, a partir da década de 1990, com a ofensiva neoliberal, inicia-se o arrefecimento do Projeto de Reforma Sanitária formulado na década de 1980. Os sucessivos governos da década de 1990 não se empenharam na construção do SUS, muito menos no avanço da RSB.

Assim, o governo de Fernando Collor de Melo caracterizouse pela crise econômica, com redução de recursos federais para a saúde, embora tenha criado o Programa dos Agentes Comunitários de Saúde (PACS), promulgado a Lei Orgânica e implantado a Norma Operacional Básica - 1991 (NOB/91) e, depois de muita protelação realizou a $9^{a}$ Conferência Nacional de Saúde.

No governo de Itamar Franco, manteve-se a crise financeira na Seguridade Social, instalando-se uma disputa inaceitável entre a saúde e a previdência, mas pode-se destacar o avanço na municipalização, a partir da Norma Operacional Básica - 1993 (NOB/93), e a criação do PSF, em 1994.

A eleição de Lula significou um marco político na história do país, pois foi a primeira vez que se elegeu "um representante da classe operária brasileira com forte experiência de organização 
política" (Braz, 2004, p.49).A consagração eleitoral foi resultado da reação da população brasileira contra o Projeto Neoliberal implantado nos anos 1990. Isto é, pela primeira vez venceu o projeto que não representa, em sua origem, os interesses hegemônicos das classes dominantes.

Entretanto, pode-se afirmar que as propostas e reformas defendidas pelo governo Lula após o seu primeiro governo dão seqüência à contra-reforma do Estado iniciada na gestão de Fernando Henrique Cardoso (FHC), uma vez que, encolheu o espaço público democrático dos direitos sociais e ampliou o espaço privado - não só nas atividades ligadas à produção econômica, mas também no campo dos direitos sociais conquistados.

Bravo (2007) ressalta que a política de saúde é apresentada no programa de governo Lula, como direito fundamental e explicita-se o compromisso em garantir acesso universal, equânime e integral às ações e serviços de saúde. No entanto, a concepção de Seguridade Social não é assumida na perspectiva da Constituição de 1988. Havia uma expectativa que o governo fortalecesse o Projeto de Reforma Sanitária na Saúde.

O governo Lula tem defendido e implementado propostas com vistas à terceirização dos trabalhadores em saúde, à criação das Fundações Estatais de Direito Privado e à fragmentação e enfraquecimento do controle social, quando cria Conselhos Curadores e Conselhos de Gestão Participativa, ao invés de fortalecer os conselhos de saúde deliberativos existentes.

No governo Lula, mesmo sem serem equacionadas as questões do financiamento e da força de trabalho do SUS, manteve-se a expansão do PSF, foi criado o Serviço de Atendimento Móvel de Urgência (SAMU), desenvolveu-se a Reforma Psiquiátrica e foram formuladas políticas nacionais de saúde bucal, atenção básica, promoção da saúde, entre outras, além de lançado o Pacto pela Saúde (Teixeira \& Paim, 2005). Também foram realizadas várias 
conferências temáticas e as XII e XIII Conferências Nacionais de Saúde.

A partir de 2003, principalmente a Abrasco (Associação Brasileira de Pós-Graduação em Saúde Coletiva), o Cebes, a Abres (Associação Brasileira de Economia da Saúde), a Rede Unida e a Ampasa (Associação Nacional do Ministério Público em Defesa da Saúde), mobilizam-se com o chamamento da necessidade de se colocar na agenda política a RSB. No ano de 2005, lançam um manifesto, em ato público realizado na Câmara dos Deputados, com vistas à defesa da aprovação da Emenda Constitucional n ${ }^{\circ} 29$ e à ampliação de mais recursos no orçamento da saúde. No ano seguinte foi lançado um documento, preparado pelo Fórum da Reforma Sanitária Brasileira (FRSB), sendo este discutido com a Frente Parlamentar da Saúde, com outras entidades dos setores de saúde e de educação e com a sociedade, com o objetivo de contribuir para as plataformas eleitorais.

O documento elaborado pelo FRSB (2006) mais uma vez foi assinado pelas entidades acima referidas com o título: O SUS pra valer: universal, humanizado e de qualidade. Dentre os aspectos abordados no documento chama a atenção "o debate necessário sobre a Reforma Sanitária e o SUS”, que aborda a questão dos obstáculos enfrentados pelo SUS que marcaram sua configuração como Sistema Nacional de Saúde, entre os mais graves destacamse: a não implementação do preceito constitucional de Seguridade Social com seus respectivos mecanismos de financiamento e gestão; o drástico sub-financiamento desde a sua criação; a profunda precarização das relações, remunerações e condições de trabalho dos trabalhadores da saúde; a insignificância de mudanças estruturantes nos modelos de atenção à saúde e de gestão do sistema; o desenvolvimento intensivo do marketing de valores de mercado em detrimento das soluções que ataquem os determinantes estruturais das necessidades de saúde. Enfatiza-se que, apesar dos referidos e reconhecidos avanços na produção, produtividade e 
inclusão, muito pouco se avançou na efetivação da integralidade, da igualdade, e só recentemente retornou-se à questão da regionalização. Ressalta-se que não será possível seguir expandindo a cobertura sem alterar os modelos de atenção e de gestão em saúde. Evidencia-se que os conselhos de saúde e a sociedade civil não têm conseguido participar com efetividade e assim influir na formulação de políticas e estratégias do SUS.

Entretanto, o FRSB, apresenta propostas que são contraditórias, tais como: a defesa do SUS humanizado e a ênfase na reposição do usuário-cidadão como o centro das formulações e operacionalização das políticas e ações de saúde.

Alguns sanitaristas também defendem propostas que se afastam dos preceitos da RSB formulada nos anos 1980, quando ressaltam a necessidade de garantir o caráter público do SUS, mas sem atrelamento do Estado,

protegendo-o da descontinuidade administrativa e de intercorrências desastrosas derivadas das manobras da política. Publicizar o SUS sem privatizá-lo, assegurando-lhe autonomia perante o Estado", governos e políticos, porém submetendo-o ao controle público e democrático mediante gestão compartilhada pela sociedade civil, trabalhadores da saúde e governo (PAIM, 2008, p. 99).

Essas perspectivas apontam para um redirecionamento dos princípios da Reforma Sanitária formulada na década de 1980, a partir principalmente das décadas de 1990 e 2000. Com ênfase, na atualidade, à sociedade civil ou terceiro setor envolvida diretamente na prestação de serviços, o que configura um verdadeiro retrocesso histórico.

Desse modo para Behring e Boschetti (2007), a tendência geral tem sido a de restrição e redução de direitos sob o argumento da 
crise fiscal do Estado, transformando as políticas sociais - a depender da correlação de forças entre as classes sociais e segmentos de classe e do grau de consolidação da democracia e da política social nos países - em ações pontuais e compensatórias direcionadas para os efeitos mais perversos da crise, prevalece o trinômio articulado do ideário neoliberal para as políticas sociais, qual seja: a privatização, a focalização e a descentralização. Sendo esta última estabelecida não como partilhamento de poder entre esferas públicas, mas como mera transferência de responsabilidades para entes da federação ou para instituições privadas e novas modalidades jurídico-institucionais correlatas, componente fundamental da reforma e das orientações dos organismos internacionais para a proteção social.

Para entender tais relações e as contradições até o momento expostas se faz necessário compreender a categoria de hegemonia, no referencial teórico gramsciano que consegue explicar os processos que implicam nas transformações societárias e defesa de interesses.Vale a pena ressaltar, que o Projeto de Reforma Sanitária Brasileira formulado na década de 1980, visava não apenas à reforma do setor saúde, mas defendia mudanças também no projeto de sociedade.

De acordo com Dias (1996) uma grande parte da literatura marxista sobre hegemonia do ponto de vista gramsciano parte da centralidade da questão de alianças de classe na sua imediaticidade política. Nessas perspectivas trabalha-se abstratamente a hegemonia como a capacidade de uma classe de subordinar/coordenar classes aliadas ou inimigas. Ressalta-se, também a partir da perspectiva do partido, no momento em que enfatiza excessivamente os mecanismos específicos da intervenção política, desconhecendo quase sempre as determinações mais complexas dessa intervenção mesmo ao nível da imediaticidade (DIAS, 1996, p.10); “essas maneiras de examinar esse conceito são restritivas e limitadoras da potencialidade de esforço teórico e prático." 
A hegemonia é pensada instrumentalmente como sendo obtenção de um domínio ideológico não se limita a uma eventual maioria nos processos políticos. A questão central ao se tratar da hegemonia é o nexo entre a capacidade de construção de uma visão de mundo e a realização da hegemonia. Esse processo de construção da hegemonia, que ocorre no cotidiano antagônico das classes decorre da sua capacidade de elaborar sua visão de mundo autônoma e da centralidade das classes.

Diferenciar-se, contrapor-se como visão de mundo às demais classes, afirmar-se como projeto para si e para a sociedade; ser direção das classes subalternas e dominadas na construção de uma nova forma civilizatória. Para tal, é fundamental ter a capacidade de estruturar o campo de lutas a partir do qual ela poderá determinar suas frentes de intervenção e articular suas alianças. A hegemonia é a elaboração de uma nova civilização. É uma reforma intelectual e moral (DIAS, 1996, p.11).

Gramsci (1971) ao empregar o termo hegemonia o fez ao referir-se ao sistema de alianças que a classe operária deve criar para derrubar o Estado burguês e servir como a base social do Estado dos trabalhadores. Valeu-se do termo para argumentar como o proletariado soviético teria de sacrificar seus interesses corporativos, econômicos, de modo a sustentar uma aliança com a classe camponesa e servir assim aos seus próprios interesses gerais.

Nas condições modernas, argumenta Gramsci (1971), uma classe mantém seu domínio não simplesmente através de uma organização específica da força, mas por ser capaz de ir além dos interesses corporativos estreitos, exercendo uma liderança moral e intelectual e fazendo concessões, dentro de certos limites, a uma variedade de aliados unificados num bloco social de forças que Gramsci chama de bloco histórico. Este bloco representa uma base 
de consentimento para uma ordem social, na qual a hegemonia de uma classe dominante é criada e recriada numa teia de instituições, relações sociais e idéias.

Embora Gramsci (1971) tenha escrito que as instituições de hegemonia estão localizadas na sociedade civil, ao passo que a sociedade política é a arena das instituições políticas no sentido constitucional jurídico, ele assinala que essa é uma divisão puramente metodológica e acentua a superposição efetiva que existe nas sociedades concretas.

A hegemonia, como é possível argumentar, não se reduz à legitimação, falsa consciência, ou instrumentalização da massa da população, cujo senso comum ou visão de mundo, segundo Gramsci é composto de vários elementos, alguns dos quais contradizem a ideologia dominante, pode propiciar uma visão de mundo mais coerente e sistemática que não só influencia a massa da população, como serve como um princípio de organização das instituições sociais.

Gramsci (1991) define o projeto histórico político do proletariado como a criação de uma sociedade regulada em que hegemonia e sociedade civil, ou seja, a área do consentimento, expandem-se plenamente, e a sociedade política, ou área de coerção, restringe-se. Isso implica que o proletariado deve criar uma expansão contínua do consentimento na qual, os interesses dos vários grupos se conjugam para formar um novo bloco histórico. Ao desenvolver uma estratégia para esse fim, uma nova hegemonia deve absorver e sistematizar elementos de idéias e práticas populares.

Segundo Duriguetto (2007) a noção de hegemonia como direção intelectual e moral assume relevância central na estratégia da guerra de posição. $\mathrm{O}$ conceito se refere tanto ao processo em que uma classe torna-se dirigente quanto à direção que uma classe no poder exerce sobre o conjunto da sociedade. A hegemonia expressa a direção e o consenso ideológico (de concepção de mundo) 
que uma classe consegue obter dos grupos próximos e aliados. Constituir-se como classe hegemônica significa construir e organizar interesses comuns e tornar-se protagonista das reivindicações de outros estratos sociais de modo a unir em torno de si esses estratos, realizando com eles uma aliança. A conquista progressiva de uma unidade político- ideológica - de uma direção de classe - requer assim, a busca do consenso dos grupos sociais aliados, alargando e articulando seus interesses e necessidades na busca da superação dos seus limites corporativos (DURIGUETTO, 2007). Nessa formulação de Gramsci estão assentados os fundamentos de uma teoria democrática da transição ao socialismo, sendo o conceito de hegemonia uma contribuição para a teoria da democracia. Ou seja, na medida em que, para o pensador italiano, a transição para o socialismo se efetivaria por meio de um processo progressivo de "democratização" e conquista de espaços políticos e de participação popular crítica e organizada nos espaços da sociedade civil, pode-se dizer que há uma relação orgânica entre hegemonia e democracia.

O desenvolvimento teórico-político da estratégia Gramsciana da guerra de posição aparece concretizado no aprofundamento progressivo da democracia política e na busca da unidade das lutas políticas imediatas das diversas organizações das classes subalternas na sociedade civil. Unidade que seria tecida através da construção de alianças cada vez mais amplas com as camadas da classe trabalhadora em torno da defesa de suas reivindicações imediatas e de profundas reformas econômicas e políticas. $\mathrm{Na}$ defesa dessa unidade consensual e hegemônica está implícita uma nova concepção de democracia e de seus institutos.

O impulso de democratização dos institutos políticos não provirá de suas formas e regras, mas da organização e pressão política das classes subalternas, e é do grau de sua consciência política e de classe, e da eficácia de suas lutas, que depende a substantividade do conteúdo dos processos democráticos. 
Na sociedade capitalista as experiências de democratização da vida social contraditoriamente têm sido sempre resultados combinado das requisições da classe trabalhadora e das necessidades do capital de se sustentar e se expandir.

Nesse momento, de reordenamento político democrático vem provando que está conseguindo adequar as necessidades do capital às conquistas da cidadania que tem expressado pela representação institucional, de composição colegiada e paritária (NETTO, 1996). Essas práticas podem até permitir a socialização da política, mas esbarram na socialização do poder político e, sobretudo, nas condições de acesso às riquezas socialmente produzidas e à propriedade.

De acordo com Sader (2002), a ideologia da democracia liberal passou a ser o horizonte mais avançado. Esse reducionismo ganhou ares de universalidade, praticamente uma consagração inconteste. A ideologia da democracia liberal busca identificar o cidadão com o consumidor e o processo eleitoral com o mercado. Essa hegemonia, ao generalizar os sistemas políticos assentados na democracia liberal, desqualificou seus interlocutores, privatizou as relações sociais e do Estado de maneira exacerbada. Ressalta que esse tipo de democracia permitiu que as relações mercantis invadissem, de tal forma, todos os espaços sociais, que o próprio tema da Reforma do Estado no Brasil ganhou conotações estritamente econômicas. Reformar o Estado deixou de ser sinônimo de sua democratização, para ser confundido com redução de suas funções reguladoras, tendo como objetivo maior o ajuste fiscal.

A democracia liberal, como modelo universal resultante de uma combinação entre os aspectos políticos, econômico e militar, foi consagrada pelo Banco Mundial e Fundo Monetário Internacional - FMI -, ao transformá-la em condição política para a concessão de empréstimos, além de direcionar as políticas sociais dos países da América Latina, destaca-se entre elas a política de saúde. 
Segundo Dias (1996, p. 35), "criou-se o mito da democracia e da democracia para todos", mas a natureza da organização econômica capitalista e, no caso do Brasil, as formas de lidar com as questões públicas e os conflitos de classe, na prática, negam a possibilidade que essa democracia se efetive ou que ultrapasse algum limite de sua formalidade. A democracia formal, a cidadania e a igualdade formal permitem forjar uma igualdade entre os estruturalmente desiguais.

No nível social, essas transformações têm provocado uma reviravolta na estrutura objetiva e ideo-subjetiva das classes sociais, tornando-as mais complexas e modificando suas hierarquias e articulações tradicionais. Mas, segundo Netto (1996, p. 93), “cabe considerar que as determinações de classes prosseguem operantes, pois é impossível apreender a dinâmica social contemporânea da ordem burguesa sem referenciá-la." A classe trabalhadora é formada por um conjunto bastante heterogêneo e, atualmente, perdeu sua grandeza estatística e parte de sua identidade política e sindical. Se essas mutações tornam mais complexas sua caracterização, parece que ocultam e escondem muito mais as características da classe que representa o capital. Ela chega a parecer invisível neste processo de transformações societárias.

Contraditoriamente, apesar de estarmos vivendo numa conjuntura de democracia esvaziada, ela talvez seja o horizonte mais imediato para a classe trabalhadora. De acordo com Netto (1996, p.09), a "democracia possibilita que os trabalhadores negociem com mais pressão a venda da única mercadoria que têm para levar ao mercado: que é a sua força de trabalho. Isto significa que a democracia política é indispensável para os trabalhadores". Nesta análise, a democracia é fundamental para que os trabalhadores se organizem, para demandar, para negociar, para crescer a sua influência na vida pública. Esse é o paradoxo da democracia. Ela é funcional à ordem do capital. Com seu desempenho não se derrota a ordem do capital, mas ela é indispensável àqueles que lutam contra a ordem do capital. 


\section{Controle social: a relação entre estado/sociedade civil e a construção de uma nova hegemonia}

O controle social tanto é empregado para designar o controle do Estado sobre a sociedade, quanto para designar o controle da sociedade sobre as ações do Estado. E, mesmo nestas duas acepções existem diferenças devido ao entendimento da função do Estado e da extensão do seu poder e/ou devido à forma de como se concebe a sociedade civil.

A perspectiva do controle da sociedade sobre as ações do Estado, tomou vulto no Brasil a partir do processo de democratização na década de 1980 e, principalmente com a institucionalização dos mecanismos de participação nas políticas públicas na Constituição de 1988 e nas leis orgânicas posteriores: os Conselhos - instâncias colegiadas de caráter permanente e deliberativo - e as Conferências Setoriais. Esta participação adquiriu uma direção de controle social posta pelos setores progressistas da sociedade, ou seja, de controle por parte dos segmentos organizados da mesma sobre as ações do Estado no sentido deste atender cada vez mais aos interesses da maioria da população, em reverso ao período ditatorial de controle exclusivo do Estado sobre a sociedade cerceando qualquer expressão desta.

Ao fazer uma leitura do referencial teórico de Gramsci, o controle social não é do Estado ou da sociedade civil, mas das classes sociais. Por isso é contraditório, pode ser de uma classe ou de outra, pois a sociedade civil enquanto momento do Estado é um espaço de luta de classes pela disputa do poder. É a partir da sua concepção de Estado - com função de manter o consenso além da sua função coercitiva - quando incorpora as demandas das classes subalternas, que se abre a possibilidade de o Estado ser controlado por essas classes, a depender da correlação de forças existente entre os segmentos sociais organizados na sociedade civil. 
Nessa concepção, conclui-se que o controle social poderá acontecer via políticas públicas. Desta forma, o controle social na perspectiva das classes subalternas visa a atuação de setores organizados na sociedade civil que as representam, na gestão das políticas públicas no sentido de controlá-las para que atendam, cada vez mais, às demandas e aos interesses dessas classes. Neste sentido, o controle social envolve a capacidade que as classes subalternas, em luta na sociedade civil, têm para interferir na gestão pública, orientando as ações do Estado e os gastos estatais na direção dos interesses destas classes, tendo em vista a construção de sua hegemonia.

Para Gramsci não existe uma oposição entre Estado e sociedade civil, mas uma relação orgânica, pois a oposição real se dá entre as classes sociais, o controle social acontece na disputa entre essas classes pela hegemonia na sociedade civil e no Estado. Somente a devida análise da correlação de forças entre as mesmas, em cada momento histórico, é que vai avaliar que classe obtém o controle social sobre o conjunto da sociedade.

Assim, o controle social é contraditório - ora é de uma classe, ora é de outra - está balizado pela referida correlação de forças. $\mathrm{Na}$ perspectiva das classes subalternas, o controle social deve se dar no sentido dessas formarem cada vez mais consensos na sociedade civil em torno do seu projeto de classe, passando do momento "econômico-corporativo" ao "ético-político", superando a racionalidade capitalista e tornando-se protagonista da história, efetivando uma "reforma intelectual e moral" vinculada às transformações econômicas. Esta classe deve ter como estratégia o controle das ações do Estado para que esse incorpore seus interesses, na medida que tem representado predominantemente os interesses da classe dominante.

$\mathrm{Na}$ contemporaneidade vários autores vêm trabalhando a concepção de controle social, porém com aportes teórico- metodológico diferenciados. Gohn (2001) afirma que o debate sobre os conselhos como instrumento de exercício da democracia esteve 
presente entre setores liberais e da esquerda em seus diferentes matizes. A diferença é que pelos liberais, eles são pensados como instrumentos ou mecanismos de colaboração, e pela esquerda como vias ou possibilidades de mudanças. Vejamos as principais tendências de alguns autores: Raichelis (2000) considera controle social como um dos elementos constitutivos da estratégia política da esfera pública. A autora defende a possibilidade de construção da esfera pública - espaço de explicitação de interesses em conflito, de confronto de projetos sociais e de luta pela hegemonia - no âmbito das políticas sociais, que envolve a participação ativa da sociedade civil na sua definição, implementação e controle.

Os conselhos de gestão setorial são novos mecanismos que dinamizam a participação social. Insere o debate sobre as relações entre democratização e representação dos interesses populares na esfera das decisões políticas.... a esfera pública implica o acesso aos processos que informam decisões da sociedade política, que devem viabilizar a participação da sociedade civil organizada na formulação e na revisão das regras que conduzem as negociações (RAICHELIS, 1998, p. 45).

Gerschman (2004) refere-se aos conselhos como mecanismos de controle social que seriam, ao mesmo tempo, resultado do processo de democratização do país e pressupostos para a consolidação dessa democracia. O fortalecimento do exercício do controle social sobre o Estado contribuiria, assim para o alargamento da esfera pública. Neste sentido, a viabilidade do controle social seria condicionada à existência de uma democracia participativa e à institucionalização dos canais de participação em conselhos setoriais.

Correia (2003) ressalta que o controle social envolve a capacidade que os movimentos sociais organizados na sociedade civil têm de interferir na gestão pública, orientando as ações do Estado 
e os gastos estatais na direção dos interesses da maioria da população. Conseqüentemente, tal perspectiva implica o controle social sobre o fundo público.

Carvalho (1995, p. 28) enfatiza que a expressão controle social é de uso recente e corresponde a uma moderna compreensão da relação Estado/sociedade, onde a esta cabe estabelecer práticas de vigilância e de controle sobre aquele. Para este autor, "o controle social inspira os conselhos de saúde para que, com a presença de segmentos sociais tradicionalmente excluídos, possam controlar o Estado", assegurando políticas de saúde pautadas pela necessidade do conjunto social.

Em contraponto às perspectivas acima, Avritzer (2008, p. 2) questiona se as proliferações de formas de representação não é uma distorção do próprio funcionamento da representação ou seria um caso entre muitos outros que tem servido para reelaborar a própria noção de representação. Para este autor à "medida que o envolvimento da sociedade civil nas políticas sociais aumentou, um problema tornou-se inescapável: o surgimento de novas formas de representação ligadas a ela."

Bravo (2006) aponta algumas tendências do controle social ao analisar os conselhos de saúde, entre as quais se destacam: 1) os conselhos têm sido percebidos como espaço consensual, onde os diferentes interesses sociais convergem para o interesse de todos. Essa concepção pautada em Habermas e nos neo-habermasianos, não leva em consideração a correlação de forças e tem adeptos inseridos nas diversas instâncias do poder político para viabilizar os conselhos a partir de seus interesses; 2) a concepção dos conselhos apenas como espaços de cooptação da sociedade civil por parte do poder público. Esta perspectiva também não percebe as contradições que podem emergir nesse espaço a partir dos interesses divergentes. Influenciada pela visão estruturalista do marxismo, cujo principal representante é Althusser. Essa posição não acredita no potencial dos conselhos e seus adeptos têm defendido a saída das entidades desses 
espaços; 3) a posição que não aceita este espaço, ou seja, questiona a democracia de base, participativa, e defende apenas a democracia representativa. Esta concepção política neoconservadora é assumida por alguns representantes governamentais, mas também tem respaldo na produção intelectual de cientistas políticos dedicados à análise da democracia e dos sistemas de representação nas sociedades capitalistas. Carlos Estevão Martins (1994), quando analisa os canais de participação de diferentes sujeitos nas decisões governamentais, pelos conselhos, considera que os mesmos são incompatíveis com a democracia representativa e; 4) a posição, que concebe os conselhos enquanto espaços contraditórios pautando-se em Gramsci, permite fazer uma análise frente aos impasses com a organização social existentes a partir da década de 1990.

Ressalta-se, que a concepção que visualiza os conselhos enquanto espaços contraditórios ou arenas de conflitos em que diferentes projetos estão em disputa está pautada em Gramsci e nos neogramscianos. No entanto, esta concepção não é hegemônica nas pesquisas existentes na área de saúde na atualidade. As visões que se contrapõem ao referencial gramsciano tem tido um impacto significativo acerca do papel político dos conselhos e conferências, sua efetividade e nas situações mais extremadas que não deve se dar mais importância a esses espaços. Tal visão tem tido um impacto significativo na relação entre Estado/sociedade. Nesta direção, Cortes (2002, p. 9) argumenta:

diferentemente do que ocorria na segunda metade dos anos 80, os conselhos e conferências de saúde na década de noventa, parecem ter deixado de ser o local principal de negociações e de mediação de interesses setoriais... A mediação entre projetos conflitantes.

A participação e a descentralização na gestão das políticas que compõem a Seguridade Social (Saúde, Assistência e Previdência Social) foram institucionalizadas no artigo 194 da Constituição 
de 1988 e detalhadas nas respectivas Leis Orgânicas posteriores. Ressalta-se que, apesar da legalidade da participação e da descentralização ter sido resultado de lutas dos setores progressistas no período de redemocratização, é preciso, contudo afirmar que a legalização trouxe problemas novos entre os quais a agregação desses movimentos aos mecanismos administrativos do Estado.

Existem dificuldades para o exercício do controle social na referida perspectiva, como: a fragilidade no nível de organização dos movimentos populares e sindicais; a pouca consciência de classe (momento meramente "econômico-corporativo" ou "egoísticopassional") dos mesmos; a cultura política de submissão arraigada na população brasileira; a baixa representatividade e conseqüente falta de legitimidade dos conselheiros, pela pouca organicidade com sua base, além da desinformação generalizada, entre outros.

Observa-se que após as fortes mobilizações e articulações dos movimentos sociais na década de 1980 e início da década de 1990 em torno da legalidade dos direitos sociais e da participação nas políticas públicas consolidadas na Constituição de 1988 e regulamentados nas Leis Orgânicas posteriores, as lutas em torno das políticas públicas passaram a acontecer nos espaços institucionais. A representação da sociedade civil organizada passou a ocupar um lugar no executivo do Estado através dos Conselhos Setoriais. Agora as disputas acontecem, principalmente, dentro dos mecanismos de participação institucionalizada - dentro dos conselhos setoriais -, e as mobilizações se dão para participar e propor nas Conferências Setoriais.

Ocorre que a atitude defensiva assumida pelos movimentos sociais, a partir dos anos 1990, tem como determinantes as mudanças na esfera do trabalho, por meio da reestruturação produtiva e das concepções pós-modernas que enfatizam apenas o local, desvalorizando categoriais mais gerais, como a totalidade social e a articulação do local com original e o nacional. A agenda dos movimentos tem sido elaborada a partir da agenda governamental, o que difere da ação dos mesmos nos anos 1980, que formulavam proposições para intervenção nas políticas públicas. 
De acordo com Bravo (2006), nesta conjuntura, de fragilização das lutas sociais, as entidades da sociedade civil não têm conseguido uma defesa da Seguridade Social e da saúde em particular, com destaque para o movimento sindical, os partidos políticos e o movimento popular.

Para Oliveira (1998), a construção da esfera pública supõe a existência de regras universais e pactuadas. O autor coloca a possibilidade de construção de uma esfera pública, mesmo nos limites do Estado burguês, negando à burguesia a propriedade do Estado e sua dominação exclusiva. A experiência do Welfare State (Estado de Bem-Estar) caracterizou-se como um padrão de financiamento público da economia capitalista, mediante estruturação de uma esfera pública (Raichelis, 1998).

Dagnino (2002) ressalta que os conselhos, por sua novidade, expressam um desafio tanto para a sociedade civil como para o Estado, em diversas dimensões, como o reconhecimento dos diferentes interesses em disputa, a capacidade de negociação sem perda de autonomia, a construção do interesse público e a ampliação da participação na formulação de políticas públicas.

Nesta perspectiva, para Bravo (2006, p. 93) "os conselhos não podem ser supervalorizados, nem subvalorizados”. São fundamentais para a socialização da informação e a formulação de políticas sociais, mas têm que ser visualizados como uma das múltiplas arenas em que se trava a disputa hegemônica no país.

\section{Considerações finais}

Uma efetiva contra-hegemonia depende de compreendermos as condições da classe subalterna, com todas as dificuldades que envolvem na atualidade. A sociedade civil é arena de luta de classes e, portanto, do embate entre aparelhos privados de hegemonia e de contra-hegemonia no sentido do convencimento, da formação, 
da educação de quadros, de sua organização segundo horizontes e projetos de classe contrapostos.

Nossas reflexões evidenciam vários desafios para a efetivação do controle social na perspectiva de dar continuidade à Reforma Sanitária Brasileira idealizada na década de 1980, uma vez que propostas privatizantes, assim como a seletividade e a focalização da política de saúde apontam interesses inconciliáveis.

Desse modo, apesar de todas as reflexões que explicitam os limites desses espaços para uma participação efetiva, considerase que esses mecanismos são importantes para a democratização do espaço público e para a mudança da cultura política brasileira. Tem-se clareza, entretanto, que esse processo é lento e precisa de investimento por parte das entidades e movimento sociais.

O controle social interpretado a partir do conceito de sociedade civil em Gramsci, requer desmistificar a aparente homogeneização desta como portadora de interesses universais, colocando como eixo de análise os antagonismos de classe que a atravessam e que são próprios das relações sociais de produção capitalista. 


\section{Referências}

AVRITZER, L. Instituições participativas e desenho institucional: algumas considerações sobre a variação da participação no Brasil democrático. Opinião Pública, Campinas, v. 14. n. 01, jun. 2008.

BANCO MUNDIAL. Relatório sobre o desenvolvimento mundial 1993: investindo em saúde. Rio de Janeiro: FGV, 1993.

BEHRING, E.; BOSCHETTI, I. Política social: fundamentos e história. São Paulo: Cortez, 2007. Biblioteca Básica de Serviço Social, v.2.

BRASIL Relatório Final da $9^{a}$ Conferência Nacional de Saúde. Brasília: Ministério da Saúde. 1992.

BRASIL. Constituição da República Federativa do Brasil. Brasília, 1988.

BRASIL. Lei n. 8.080 de 19 de set. de 1990. Dispõe sobre as condições para a promoção, proteção e recuperação da saúde, a organização e o funcionamento dos serviços correspondentes e dá outras providências. Diário Oficial da União, Brasília, DF, 19 de setembro de 1990; $169^{\circ}$ da Independência e $102^{\circ}$ da República.

BRASIL. Lei no 8.142 de 28 de dez. de 1990. Dispõe sobre a participação da comunidade na gestão do Sistema Único de Saúde e sobre as transferências intergovernamentais de recursos financeiros na área da saúde e dá outras providências. Diário Oficial da União, Brasília, DF, 28 de dezembro de $1990 ; 169^{\circ}$ da Independência e $102^{\circ}$ da República.

BRASIL. Norma Operacional Básica de 1991. Brasília: Ministério da Saúde, 1991.

BRASIL. Norma Operacional Básica de 1993. Brasília: Ministério da Saúde, 1993.

BRASIL. Relatório Final da $12^{\mathrm{a}}$ Conferência Nacional de

Saúde. Brasília: Ministério da Saúde. 2004. 
BRASIL. Relatório Final Preliminar da $13^{\mathrm{a}}$ Conferência

Nacional de Saúde. Brasília: Ministério da Saúde. 2007.

BRAVO, M. I. S. Desafios atuais do controle social no Sistema Único de Saúde (SUS). Serviço Social e Sociedade. São Paulo, n. 88, p. 00-00, 2006.

BRAVO, M. I. S. Serviço social e saúde: desafios atuais. Temporalis, Brasília, v. 1, p. 121-150, 2007.

BRAVO, M. I. S. Política de saúde e serviço social: impasses e desafios. Temporalis, São Luis, nº 13, 2007.

BRAZ, M. O governo Lula e o projeto ético-político do Serviço Social. Serviço Social \& Sociedade, nº. 78. São Paulo: Cortez, 2004.

CARVAlHO, A. I. Conselhos de Saúde no Brasil: participação cidadã e controle social. Rio de Janeiro, FASE/IBAM, 1995.

CORREA, M.V. C. Reflexos da capacitação na atuação dos conselheiros de saúde. Saúde em Debate, Rio de Janeiro, v. 27, n. 64, p 138 -147 , mai/ago.2003.

CORTES, S. M.V. Construindo a possibilidade da participação dos usuários: conselhos e conferências no Sistema Único de Saúde. Sociologias, Porto Alegre, n. 7, jan/jun. 2002.

DAGNINO. E. Sociedade Civil e Espaços Públicos no Brasil. Rio de Janeiro: Paz e Terra, 2002.

DIAS, E. F. Hegemonia: racionalidade que se faz história. In: O outro Gramsci. São Paulo: Xamã, 1996.

DURIGUETTO, Maria Lúcia. Sociedade civil e democracia: um debate necessário. São Paulo: Cortez, 2007.

FLEURY, Sonia. Reforma Sanitária: em busca de uma teoria. São Paulo, Rio de Janeiro: Cortez, Abrasco, 1989. 


\section{FÓRUM DA REFORMA SANITÁRIA BRASIEIRA.}

Documento. Rio de Janeiro, 2006.

FÓRUM DA REFORMA SANITÁRIA BRASIEIRA. Manifesto. Brasília, 2005.

GERSCHMAN, S. A Democracia Inconclusa: um estudo da Reforma Sanitária Brasileira. Rio de Janeiro: Fiocruz, 1995.

GERSCHMAN, S. Conselhos Municipais de Saúde: atuação e representação das comunidades populares. Cadernos de Saúde Pública.V. 20, n. 6. Rio de Janeiro, nov/dez.2004.

GOHN, M. G. Conselhos gestores: participação sócio-política. São Paulo: Cortez, 2001. (Questões da Nossa Época).

GRAMSCI, A. La Política y el Estado Moderno. Barcelona, Ediciones Península, 1971.

GRAMSCI, A. Maquiavel, a política e o Estado moderno. 4. ed. Rio de Janeiro: Civilização Brasileira, 1991.

MARTINS, Carlos Estevan. O circuito do poder. São Paulo: Èntrelinhas, 1994

MOTA, Ana Elizabete. Cultura da crise e seguridade social. $1^{\mathrm{a}}$ ed. São Paulo: Cortez, 1995.

NETTO, José Paulo. Transformações societárias e Serviço Social - notas para uma análise prospectiva da profissão no Brasil. Serviço Social e Sociedade, $n^{\circ}$ 50, 1996.

Oliveira, Francisco. Os direitos do antivalor: a economia política da hegemonia imperialista. Petrópolis:Vozes, 1998.

PAIM, J. S. Desafios da gestão democrática das políticas sociais. In: Capacitação em Serviço Social e política social. Módulo 3. Brasília: UnB, Centro de Educação Aberta, Continuada a Distância, 2000. 
PAIM, J. S.; TEIXEIRA, C. F. Configuração institucional e gestão do Sistema Único de Saúde: problemas e desafios. Ciência e Saúde Coletiva, $\mathrm{n}^{\circ}$ 12, 2007.

PAIM, J. S. Reforma Sanitária Brasileira: avanços, limites e perspectivas. In: Estado, Sociedade e Formação Profissional em Saúde - contradições e desafios em 20 anos de SUS. (Org) MATTA, Gustavo Correa. Rio de Janeiro: Editora Fiocruz/EPSJV, 2008.

RAICHELIS, R. Assistência Social e esfera pública: os conselhos no exercício do controle social. In Serviço Social e Sociedade. São Paulo: Cortez, n. 56, p. 77-96, 1998.

SADER. E. Para outras democracias. In: Santos, B.S. (org.) Democratizar a democracia: os caminhos da democracia participativa. Rio de Janeiro: Civilização Brasileira, 2002, p. 649-678. 